\title{
Electrolysis Oxidation of Chalcopyrite and Molybdenite for Selective Flotation
}

\author{
Hajime Miki*, Hidekazu Matsuoka, Tsuyoshi Hirajima, Gde Pandhe Wisnu Suyantara and Keiko Sasaki \\ Department of Earth Resources Engineering, Kyushu University, Fukuoka 819-0395, Japan
}

\begin{abstract}
Electrolysis oxidation of chalcopyrite and molybdenite was investigated, via various electrochemical methods, with the aim of realizing selective flotation of these minerals. Result of potential polarization indicated that oxidation via electrolysis affected only the chalcopyrite surface, owing mainly to the difference in conductivity of these minerals. Also measurements of contact angle after electrolysis indicated that contact angle of chalcopyrite selectively decreased whereas that of molybdenite did not decrease drastically. XPS analyses after electrolysis indicated that chalcopyrite peak decreased whereas iron oxyhydroxide (goethite) and iron sulfate increased, it suggests that these oxidation products covered on the surface of chalcopyrite. On the other hand, molybdenite peak is similar after electrolysis except for molybdenum oxide/ oxygen with molybdenite can be seen for oxygen peak. From these results and general knowledge that sulfide hydrophobicity and sulfate/ oxyhydroxide hydrophilicity, it can be explained that with electrolysis oxidation, hydrophilic oxihydroxide and sulfate covered on the surface of hydrophobic chalcopyrite then chalcopyrite surface became hydrophilic. On the other hand, molybdenite surface keep hydrophobic since its difficulty of oxidation and it is difficult to stay molybdenum oxide on the surface due to its soluble property. These results revealed that chalcopyrite was selectively oxidized and, hence, selective flotation of chalcopyrite and molybdenite was possible. This electrolysis oxidation methods were compared with those governing other oxidation treatments. [doi:10.2320/matertrans.M-M2017807]
\end{abstract}

(Received July 12, 2016; Accepted January 23, 2017; Published March 27, 2017)

Keywords: selective flotation, electrolysis, oxidation, chalcopyrite, molybdenite, XPS

\section{Introduction}

Many copper mines in South America produce molybdenite $\left(\mathrm{MoS}_{2}\right)$ as a byproduct mineral ${ }^{1)}$. Separation of these minerals is difficult, and molybdenite contamination of the copper concentrate indicates loss of the molybdenum source. This contamination also reduces the value of the concentrate. Similarly, copper contamination of the molybdenum concentrate reduces the value of the concentrate and, hence, an additional copper leaching process is required. Conventional separation of copper sulfide and molybdenite has been achieved through sulfide bulk flotation followed by selective molybdenite flotation with NaHS addition (NaHS acts as a depressant for copper sulfide ${ }^{2,3)}$ ). However, this process yields incomplete molybdenite recovery ${ }^{4,5)}$ and depressants, such as $\mathrm{NaHS}$, must be used under a specific closed-system flotation plant $^{6)}$ therefore alternative process is required. There is report about the effect of pulp potential on selective flotation, it suggests that recovery of chalcopyrite and molybdenite is different with specific pulp potential ${ }^{7)}$. From this knowledge, authors has proposed alternative selective flotation process with an oxidation pretreatment system ${ }^{8,9)}$. The operating principle of this process is based on the difference in the oxidation tendency of chalcopyrite $\left(\mathrm{CuFeS}_{2}\right)$, the most important copper mineral, and molybdenite. In fact, with oxidation, chalcopyrite becomes more hydrophilic than molybdenite since coverage of hydrophilic sulfate/hydroxide and, hence, selective flotation may be employed. Various oxidation methods, including plasma oxidation ${ }^{8)}$ and ozone oxidation ${ }^{9)}$, have been proposed. However, the phenomena occurring during these processes and the reaction required to achieve an effective process must be elucidated. In this study, electrolysis oxidation (performed via various electrochemical techniques) was used to investigate the oxidation phenomena associated with chalcopyrite and molybdenite. Aim of electrolysis oxidation is same as other oxidation process: from the difference

*Corresponding author, E-mail: miki@mine.kyushu-u.ac.jp of oxidation tendency of chalcopyrite and molybdenite, surface of chalcopyrite is oxidized selectively and covered hydrophilic oxidation products then chalcopyrite became sink and molybdenite stay float to achieve selective flotation. Laser microscopic observations and XPS were also performed to elucidate the effect of electrolysis oxidation on the floatability. The oxidation effect associated with electrolysis was compared with that of ozone treatment method and plasma oxidation. In addition, electrochemical measurements, contact angle measurements to estimate the oxidation effect, and various surface analysis and flotation experiments were conducted and the feasibility of each oxidation method was determined.

\section{Experimental Material and Methods}

\subsection{Material}

Pure crystal chalcopyrite (Miyatamata mine, Japan) and molybdenite (Hirase mine, Japan) were used as specimens in this study. Result of XRD pattern indicated that chalcopyrite sample contains chalcopyrite peak and silica small peaks. Molybdenite sample contains only molybdenite peak. Chemical composition of these minerals are as follows: for chalcopyrite, $\mathrm{Cu} 34.6 \%$, Fe $29.0 \%$, S 33.7\%, Si 7.9\%. For molybdenite, Mo $60.0 \%$, S 39.5\%. For XPS analysis, contact angle measurements, and electrochemical measurements, a large electrode sample was prepared as follows: a flat sample was cut and cemented with epoxy resin (Technovit 3040, Heraeus Kulzer, Germany). One side of the surface was used as the electrode surface and the other was connected to copper wire and conductive silver paste (Silver Paste DGP80 TESM8020, Sigma-Aldrich, Germany) as an electrode connector. Because molybdenite is a layered cleavage-sheet-structure mineral, two types of electrodes were prepared such that the electrode surface direction is (i) parallel and (ii) perpendicular to the layered structure. The corresponding electrodes are referred to as "surface" and "edge" electrodes, respectively. In preparation for each experiment, the mineral surface was exposed by 
polishing with \#800 to \#4000 emery paper, Texmet (Buehler, USA) perforated non-woven pat, and DP-Nap (Struers, Germany) fine polishing cloth (mounted on a plate), using $3-\mu \mathrm{m}$ and $1-\mu \mathrm{m}$ diamond spray as an abrasive. Electrode surface area is as follows: chalcopyrite electrode $0.86 \mathrm{~cm}^{2}$, molybdenite edge electrode $0.28 \mathrm{~cm}^{2}$, molybdenite surface electrode $0.88 \mathrm{~cm}^{2}$. All chemicals used in this report to prepare electrolyte $\left(\mathrm{KCl}, \mathrm{H}_{2} \mathrm{SO}_{4}, \mathrm{KOH}\right)$ is analytical grade and water is used as de-ionized and double distilled water.

\subsection{Electrochemical measurement and treatment}

A conventional three-electrode electrolytic cell was used for electrochemical analysis with a potentiostat (1205B, ALS Co., Ltd.). The prepared mineral electrode, a platinum electrode, and an $\mathrm{Ag} / \mathrm{AgCl}$ electrode were used as the working, counter, and reference electrodes, respectively. All electrode potentials in this study are reported with respect to the SHE. In addition, the $\mathrm{pH}$ of the electrolyte, i.e., $10^{-3} \mathrm{M} \mathrm{KCl}$, was adjusted by using $\mathrm{H}_{2} \mathrm{SO}_{4}$ or $\mathrm{KOH}$. The potentiodynamic polarization experiments were conducted at a potential sweep rate of $10 \mathrm{mV} / \mathrm{s}$ and the potential was swept from the open circuit potential to $1.4 \mathrm{~V}$, at electrolyte $\mathrm{pH}$ values of 4,9 , and 11. During these experiments, a constant potential of 1.0, 1.2, and $1.4 \mathrm{~V}$ was applied for $800 \mathrm{~s}$.

\subsection{Contact angle measurement}

The contact angle of the mineral was measured using a Goniometer (Dropmaster 300, Kyowa Interface Science Co., Ltd.), after potentiostatic polarization in an electrolyte solution ( $\mathrm{pH}$ of 9). A micro syringe was used to attach $0.1 \mu \mathrm{L}$ of air bubbles to the mineral surface and the contact angle was measured directly, via microscopic observation, for $50 \mathrm{~s}$. This process was repeated three times at different spots on the mineral surface. The average value of the readings is reported here.

\subsection{X-ray photoelectron spectroscopy (XPS)}

The untreated and treated mineral samples were analyzed via X-ray photoelectron spectroscopy (XPS; AXIS 165, Shimadzu-Kratos Co., Ltd.) using an $\mathrm{Al} \mathrm{K} \alpha$ X-ray source $(1486.6 \mathrm{eV})$ operated at $105 \mathrm{~W}$. A charge neutralizer was used for the measurements and a $1 \mathrm{~mm} \times 1 \mathrm{~mm}$ analysis area was obtained. The pressure in the analyzer chamber was maintained at $10^{-8} \mathrm{~Pa}$ during analysis. The samples were first examined via wide scanning ( $80 \mathrm{~W}$ of the analyzer pass energy) to identify the elements present. Various elemental regions were then scanned ( $40 \mathrm{~W}$ of the analyzer pass energy) to extract information on chemical bonding and the oxidation stage. The collected data were analyzed with the Casa XPS software (Ver, 2.3.16), and background corrections were performed by using the Shirley method ${ }^{10)}$ for the C1s, O1s, Fe $2 \mathrm{p}$, $\mathrm{Cu} 2 \mathrm{p}, \mathrm{S} 2 \mathrm{p}$, and Mo3d spectra. Furthermore, the peak shapes were defined and the binding energy $\left(E_{B}\right)$ was calibrated using a Gaussian-Lorentzian function and $\mathrm{C} 1 \mathrm{~s}$ at $E_{B}[\mathrm{C} 1 \mathrm{~s}]=$ $284.8 \mathrm{eV}$ as the reference, respectively.

\section{Results and Discussion}

\subsection{Potential polarization experiment}

The surface-oxidation susceptibility of chalcopyrite and molybdenite was investigated, via electrolysis, by subjecting chalcopyrite and molybdenite electrodes to polarization in $10^{-3} \mathrm{M} \mathrm{KCl}$ (at $\mathrm{pH}$ of 4,9 , and 11). During polarization, the potential was varied at a rate of $10 \mathrm{mV} / \mathrm{s}$, from the open circuit potential, along the anodic direction. Figure 1 (A), (B), and $(\mathrm{C})$ show the results obtained at $\mathrm{pH}$ values of 4,9 , and 11 , respectively. As the figure shows, the current density increases with increasing potential and $\mathrm{pH}$, especially in the case of the chalcopyrite electrode. At high potentials, the current density of the chalcopyrite electrode and the molybdenite edge electrode is significantly higher and moderately higher than that of the molybdenite electrode and molybdenite surface electrode, respectively. Therefore, at high potentials, the oxidation rate on chalcopyrite is considerably higher than that of molybdenite. The resistance of chalcopyrite, molybdenite edge, and molybdenite surface electrodes was measured with a multimeter and values of $234 \Omega, 1.2 \mathrm{M} \Omega$, and $1.5 \mathrm{M} \Omega$, respectively, were obtained. The difference in the current density of chalcopyrite and molybdenite results from the resistance of these minerals. In addition, the current density of the mo-
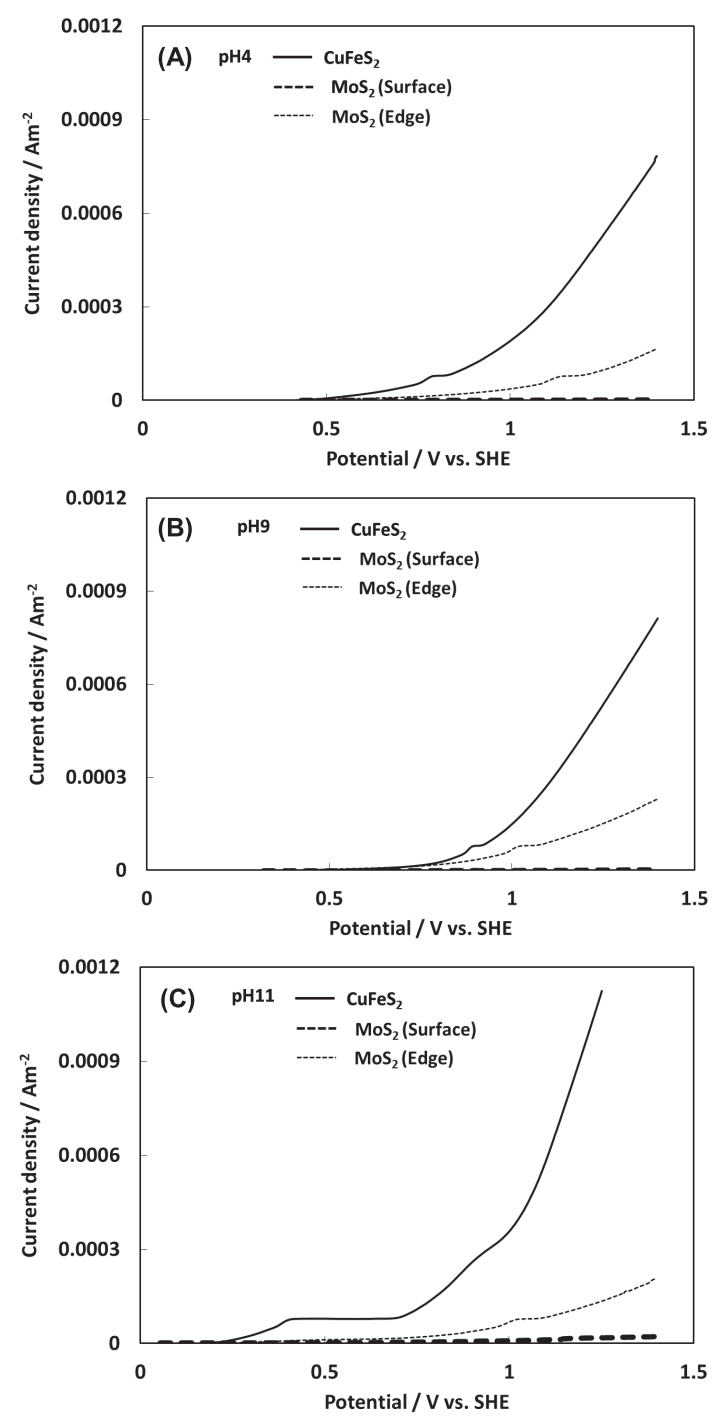

Fig. 1 Results of potential polarization experiments performed on chalcopyrite and molybdenite electrodes (Surface, Edge). The potential was varied from the open circuit potential to $1.4 \mathrm{~V}$, along the anodic direction, at a scan rate of $10 \mathrm{mV} \mathrm{s}^{-1}$. Experiments were performed at $\mathrm{pH}$ values of 4 (A), 9 (B), and $11(\mathrm{C})$. 
lybdenite edge electrode is always significantly higher than that of the molybdenite surface electrode. Previous studies ${ }^{11)}$ have shown that molybdenite is a layered cleavage mineral where the mineral-cleavage surface structure and mineral edge structure consist of sulfur atoms, and molybdenum atoms with partly broken bonds, respectively. In other words, the molybdenite surface is more stable than the molybdenum edge and, hence, the edge is more easily oxidized than the surface. This anisotropic property also reported by previous studies ${ }^{11)}$. This is confirmed by the aforementioned results, i.e., the current density of the chalcopyrite electrode increases with increasing potential and $\mathrm{pH}$, indicative of the respective oxidation and acid-production characteristics of the reaction. For chalcopyrite, Hackl et al. ${ }^{12)}$ indicated that chalcopyrite shows passivation at the potential $0.6-0.9 \mathrm{~V}$ whereas at high potential it is oxidized as following reaction ${ }^{13)}$.

$\mathrm{CuFeS}_{2}+8 \mathrm{H}_{2} \mathrm{O}=\mathrm{Cu}^{2+}+\mathrm{Fe}^{2+}+2 \mathrm{SO}_{4}^{2-}+16 \mathrm{H}^{+}+16 \mathrm{e}^{-}$

At this weak alkali pH condition, copper and iron ions precipitates since precipitation form is the stable species according to $\mathrm{pH}$-Eh diagram ${ }^{8,9)}$. These reaction can be expressed as following reaction.

$$
\begin{gathered}
\mathrm{Fe}^{3+}+3 \mathrm{OH}^{-}=\mathrm{Fe}(\mathrm{OH})_{3} \\
\mathrm{Fe}^{3+}+3 \mathrm{OH}^{-}=\mathrm{FeOOH}+\mathrm{H}_{2} \mathrm{O} \\
2 \mathrm{Fe}^{3+}+3 \mathrm{SO}_{4}{ }^{2-}=\mathrm{Fe}_{2}\left(\mathrm{SO}_{4}\right)_{3} \\
2 \mathrm{Cu}^{2+}+\mathrm{O}_{2}=2 \mathrm{CuO}
\end{gathered}
$$

For molybdenite, it is difficult to oxidize because of its high resistance but Chander and Fuersteuau ${ }^{14)}$ indicated following oxidation reaction:

$$
\mathrm{MoS}_{2}+8 \mathrm{OH}^{-}=\mathrm{MoO}_{4}{ }^{2-}+2 \mathrm{SO}_{4}{ }^{2-}+4 \mathrm{H}_{2} \mathrm{O}+6 \mathrm{e}^{-}
$$

If solution contains dissolved oxygen, following reaction might occur from the $\mathrm{pH}$-Eh diagram ${ }^{8,9)}$.

$$
2 \mathrm{MoS}_{2}+7 \mathrm{O}_{2}=2 \mathrm{MoO}_{3}+4 \mathrm{SO}_{4}{ }^{2-}
$$

\subsection{Electrolysis oxidation treatment}

Electrolysis oxidation was investigated by performing 800 -s potential static experiments, at 1.0-1.4 V, on chalcopyrite and molybdenite (surface, edge) electrodes in $10^{-3} \mathrm{M}$ $\mathrm{KCl}$ solution ( $\mathrm{pH}$ of 9). Figure 2 (A), (B), and (C) show the results obtained at static potentials of $1.0 \mathrm{~V}, 1.2 \mathrm{~V}$, and $1.4 \mathrm{~V}$, respectively. As in the case of potential polarization, the current density of chalcopyrite is significantly higher than that of molybdenite. Similarly, the current density of the molybdenite edge is higher than that of the molybdenite surface electrode. These results, like those of the potential polarization experiments, are attributed to the oxidation susceptibility. However, the current density of chalcopyrite at $1.4 \mathrm{~V}$ is considerably lower than the values obtained at $1.0 \mathrm{~V}$ and $1.2 \mathrm{~V}$. This results possibly from increased precipitation (such as copper and iron hydroxide and/or oxyhydroxide) that occurs on the surface of chalcopyrite when the potential is increased.

Electrolysis-treated or untreated chalcopyrite and molybdenite surface electrodes were observed, at $200 \times$ magnifica-
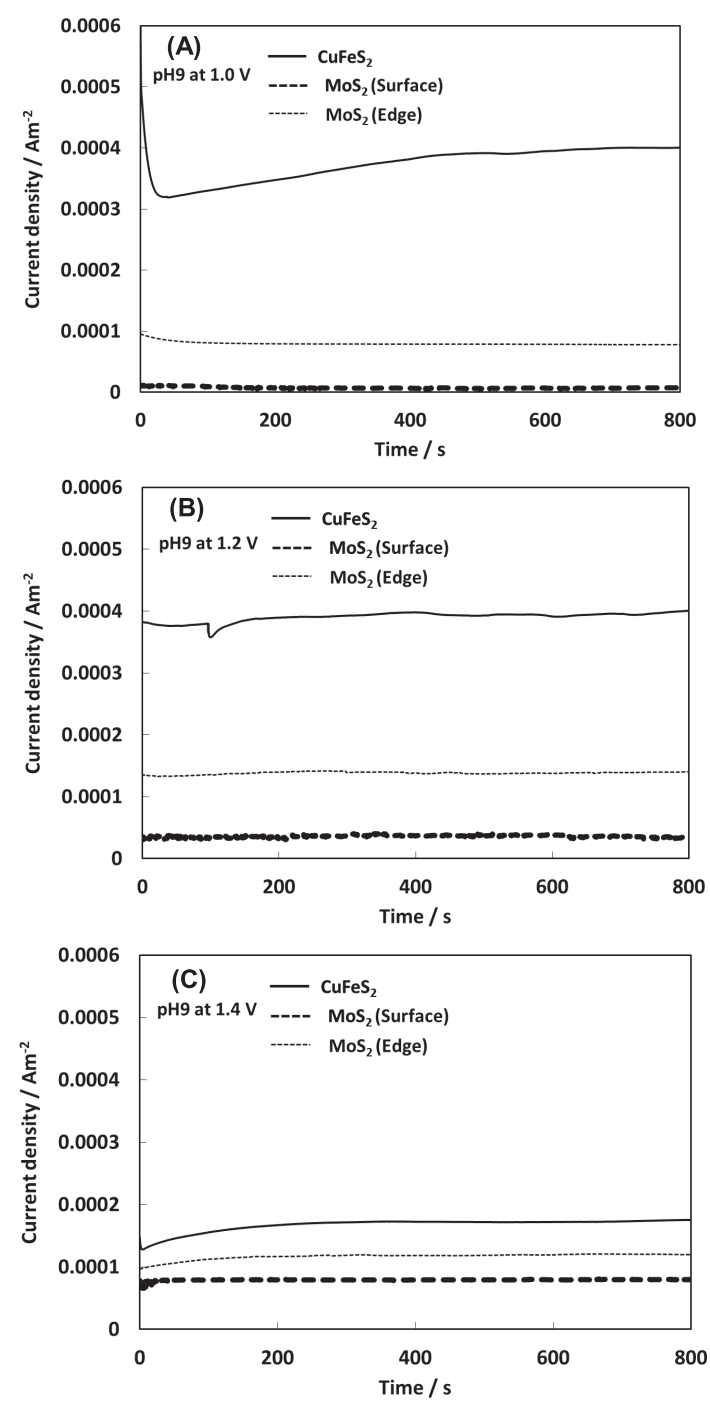

Fig. 2 Results of potential static experiments performed on chalcopyrite and molybdenite electrodes (Surface, Edge). Experiments were performed at $1.0 \mathrm{~V}(\mathrm{~A}), 1.2 \mathrm{~V}(\mathrm{~B})$, and $1.4 \mathrm{~V}(\mathrm{C})$, for $800 \mathrm{~s}$, in $10^{-3} \mathrm{M} \mathrm{KCl}$ $(\mathrm{pH}=9)$ solution.

tion, by using a laser microscope (Model VK-X-200, Keyence Co., Ltd.). Micrographs of the untreated and electrolysis-oxidized chalcopyrite, molybdenite surface, and edge electrodes are shown in Fig. 3. As the figure shows, the color of the chalcopyrite surface changed from yellow (in the untreated state) to blue after electrolysis oxidation. The color of the molybdenite surface electrode appears unchanged with oxidation, whereas the molybdenite edge electrode becomes darkened. These results show that the surface oxidation results from electrolysis oxidation.

After $800 \mathrm{~s}$ of electrolysis, the electrode was left for a specified time and then the contact angle was measured. Floatability is influenced by the contact angle, and low floatability in aqueous solutions is indicative of high wettability and low contact angle. Figure 4 shows the result of contact angle measurements performed on the chalcopyrite (A) and molybdenite (B) surfaces. The figure also shows the transition of the contact angle after $800 \mathrm{~s}$ of electrolysis at 1.0,1.2, and $1.4 \mathrm{~V}$ and after being left in the electrolyte for 5-120 min. Assessment of the molybdenite edge electrode was impossible because, owing to its layered structure, bubbles were absorbed 

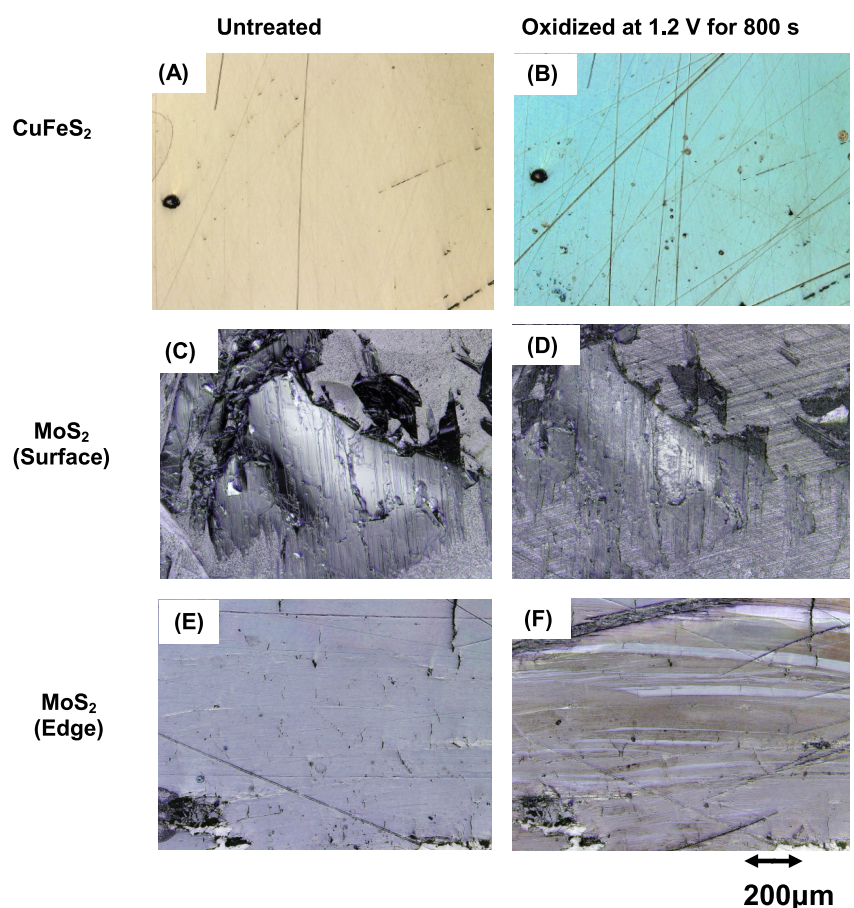

Fig. 3 Laser microscopy images (obtained at a magnification of $200 \times$ ) of chalcopyrite and molybdenite (Surface, Edge) with or without electrolysis oxidation at $1.2 \mathrm{~V}$, for $800 \mathrm{~s}$, in $10^{-3} \mathrm{M} \mathrm{KCl}(\mathrm{pH} 9)$ solution. Chalcopyrite without oxidation (A), with oxidation (B), molybdenite surface without oxidation (C), with oxidation (D), molybdenite edge without oxidation (E), and with oxidation (F).
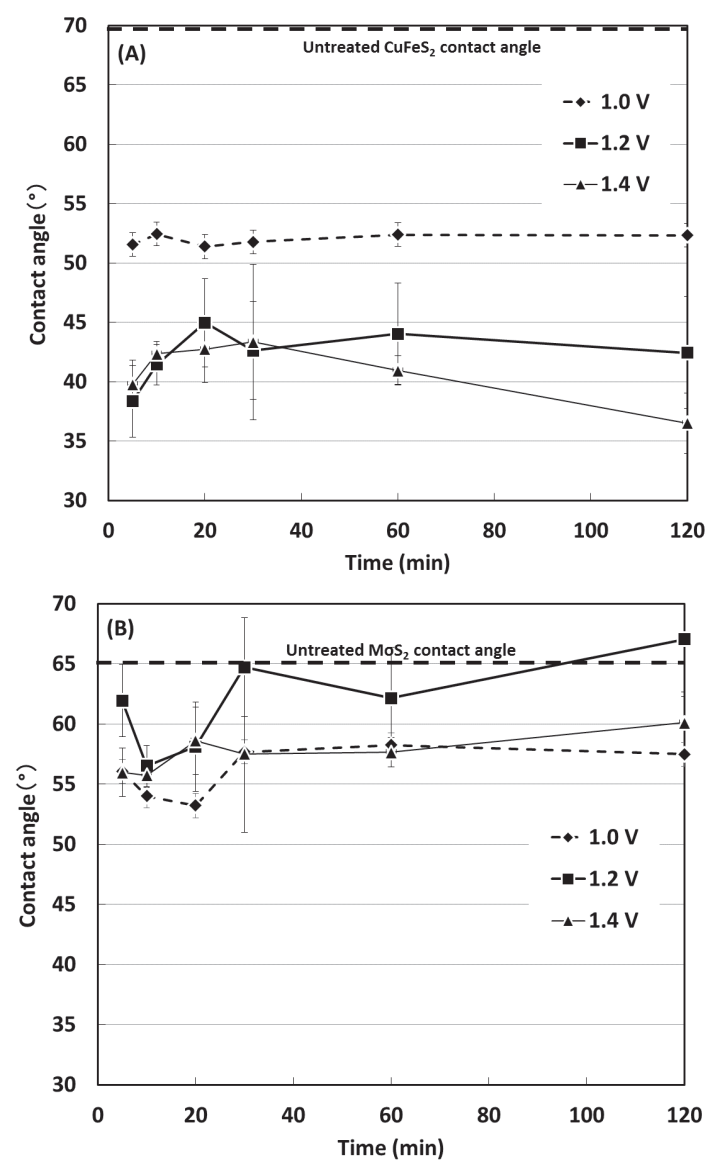

Fig. 4 Contact angle measurement of chalcopyrite (A) and molybdenite (B) surface electrodes subjected to electrolysis and retention. by the electrode during the measurement. The dashed line in the figure corresponds to the contact angle of the untreated chalcopyrite and molybdenite. Although measurement error is quite high since oxidation state is different with the place of electrode surface, as the figure shows, we can see the trend that the contact angle of the treated chalcopyrite electrode decreases, in general, with increasing applied potential and is significantly lower than that of the untreated chalcopyrite. In contrast, the contact angle on the molybdenite electrode appeared to be relatively independent of the applied potential. This indicates that electrolysis oxidation selectively changes the wettability of chalcopyrite and, hence, may be employed for selective flotation of chalcopyrite and molybdenite.

Selective conversion of mineral wettability by electrolysis oxidation may be explained by previous studies. Electrochemical experiments have revealed that the conductivity and oxidation rate of chalcopyrite is considerably higher than those of molybdenite. Although the chalcopyrite surface is oxidized, molybdenite is only slightly influenced by the electrolysis treatment. Furthermore, according to thermodynamic calculations ${ }^{8,9)}$, copper and iron released from the chalcopyrite surface can be deposited as oxides or oxyhydroxides, whereas, under this condition, molybdenite-oxide species can exist stably as ions. This indicates that the chalcopyrite surface is covered by iron and/or copper oxides, whereas the molybdenite surface remains uncovered.

\subsection{XPS surface analysis for electrolysis oxidation treat- ment}

The electrolysis-induced changes in the surface were confirmed by performing XPS surface analysis of molybdenite and chalcopyrite before and after electrolysis. Figure 5 shows the XP spectra of chalcopyrite: Cu 2p (A), Fe 2p (B), O 1s (C), and S 2p (D). The O 1s spectra show that the sulfate and oxyhydroxide (goethite, $\mathrm{FeOOH}$ ) peak intensities increased after the electrolysis oxidation treatment. The sulfate peak intensity decreased with increasing retention time after electrolysis, whereas the goethite peak intensity remained high even after 120 min. However, the Fe 2p spectra indicate that goethite was formed on the oxidation-treated chalcopyrite surface and its peak intensity remained high even after prolonged periods. The peak intensity decreased significantly after electrolysis, owing possibly to goethite coverage of the surface. This is confirmed by the $\mathrm{Cu} 2 \mathrm{p}$ spectra (Fig. 5(A)), where the chalcopyrite peak intensity decreased after electrolysis. Moreover, the S 2p spectra reveal that the decrease in chalcopyrite peak intensity is followed by the occurrence of sulfur and sulfate at high binding energies. The sulfate peak intensity decreased gradually with increasing retention time. These results suggest that electrolysis oxidation produces iron oxyhydroxide and sulfate, which is considered equivalent to iron sulfate. When the retention time is increased, iron sulfate decomposes into sulfate and iron ions. From $\mathrm{pH}-\mathrm{Eh}$ diagram, this dissolved iron might be precipitated as iron oxyhydroxide. On the other hand, iron oxyhydroxide remains stable on the chalcopyrite surface, even after prolonged retention, or precipitates as iron oxyhydroxide.

Figure 6 shows the XP spectra of molybdenite: Mo 3d (A), $\mathrm{O} 1 \mathrm{~s}(\mathrm{~B})$, and S 2p (C). The binding energy $(533.3 \mathrm{eV})$ of oxygen/molybdenum disulfide in the $\mathrm{O} 1 \mathrm{~s}$ spectra indicates 

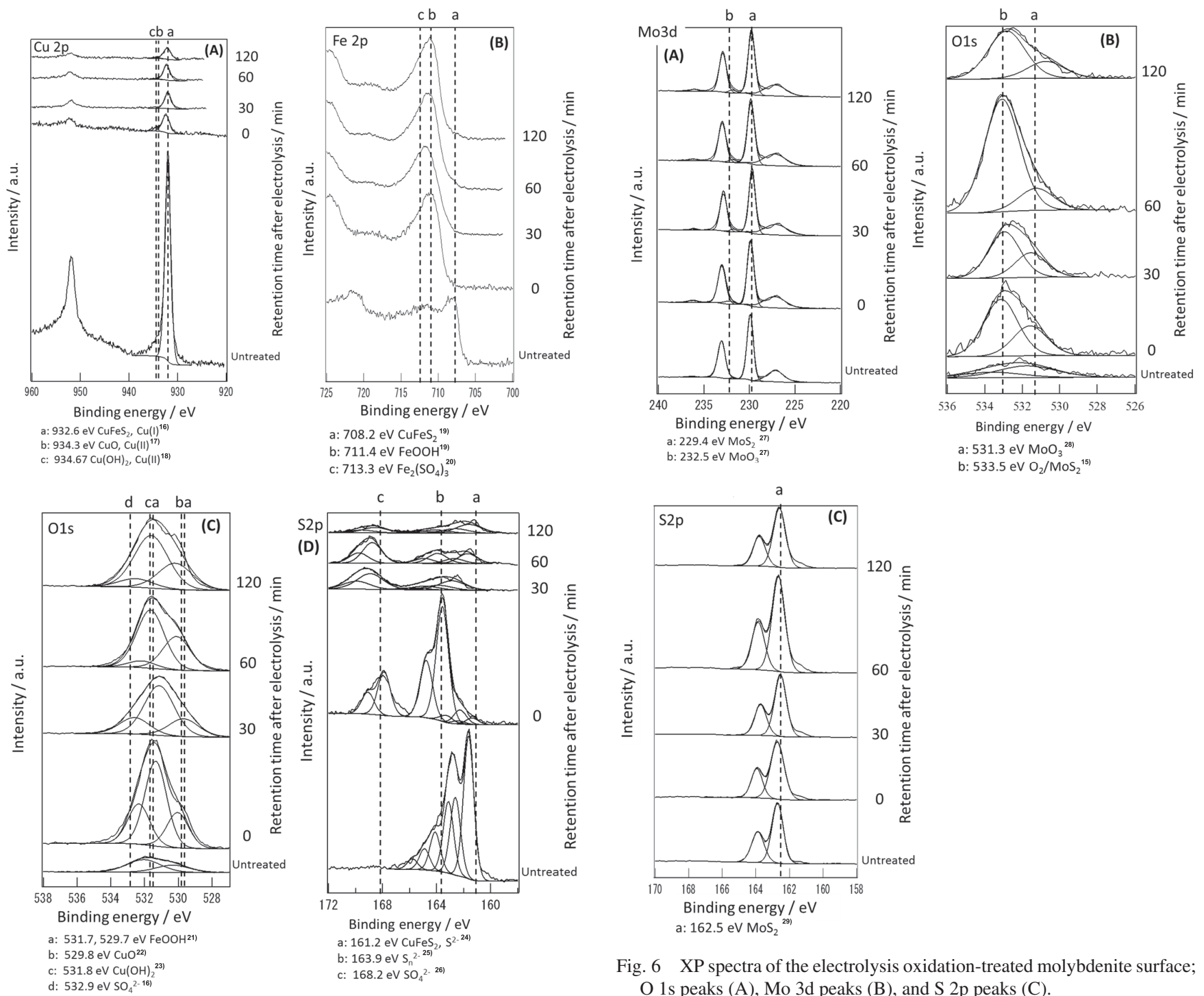

Fig. 6 XP spectra of the electrolysis oxidation-treated molybdenite surface; $\mathrm{O} 1 \mathrm{~s}$ peaks (A), Mo 3d peaks (B), and S 2p peaks (C).

Fig. 5 XP spectra of the electrolysis oxidation-treated chalcopyrite; $\mathrm{Cu} 2 \mathrm{p}$ peaks (A), Fe 2 p peaks (B), O 1s peaks, and $S 2 p$ peaks (D).

that oxygen is attached to the surface of the molybdenum lay$\mathrm{er}^{15)}$. As the $\mathrm{O} 1 \mathrm{~s}$ peaks (Fig. 6(B)) show, the peak intensities of the oxide and oxygen/molybdenum increased after the electrolysis oxidation treatment. However, these intensities decreased gradually after prolonged retention. The Mo $3 \mathrm{~d}$ and S $2 p$ spectra obtained before and after electrolysis oxidation differ only slightly, as shown in Fig. 6(A) and (C).

Therefore, electrolysis oxidation oxidizes the molybdenite surface slightly and oxygen becomes attached to the surface of the molybdenite layer. With prolonged retention after electrolysis oxidation, molybdenum oxide can dissolve as molybdenum oxide ions, such as $\mathrm{MoO}_{4}{ }^{2-}$, as indicated by the $\mathrm{pH}$ Eh diagram ${ }^{8,9)}$. As a result, the molybdenite surface becomes hydrophobic with prolonged retention.

From these results, possible phenomenon with electrolysis oxidation can be summarized in Fig. 7. Both untreated chalcopyrite and molybdenite are hydrophobic. With electrolysis oxidation, chalcopyrite became hydrophilic since hydrophilic iron sulfate and iron oxyhydroxide covered on the surface. With retention in electrolyte after electrolysis, iron sulfate dissolved and replaced with iron oxyhydroxide because of

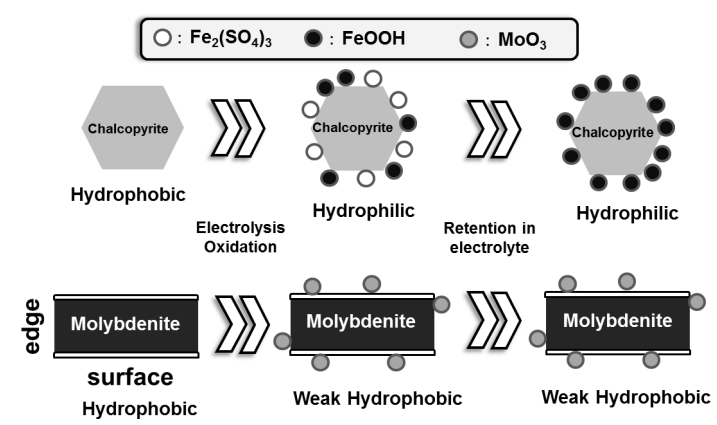

Fig. 7 Schematic figure of electrolysis oxidation treatment of chalcopyrite and molybdenite.

re-precipitation then surface keep hydrophilic. On the other hand for molybdenite, with electrolysis oxidation, molybdenum oxide produced but surface keep weak hydrophobic since molybdenum oxide is soluble. With retention in electrolyte after electrolysis, surface keep weak hydrophobic since still small amount of molybdenum oxide stayed on the surface. 
Table 1 Contact angle (degrees, ${ }^{\circ}$ ) of the chalcopyrite and molybdenite oxidized via various oxidation methods.

\begin{tabular}{|c|c|c|c|c|c|}
\hline & Untreated & Electrolysis at $1.2 \mathrm{~V}$ & Ozone for $30 \mathrm{~min}$ & Plasma treated & Washed for $120 \mathrm{~min}$ after Plasma \\
\hline Chalcopyrite & 71.7 & $42.4(29.3)$ & $30.2(41.5)$ & $26.0(45.7)$ & $63.1(8.6)$ \\
\hline Molybdenite & 68.6 & $67.0(1.6)$ & $40.8(27.8)$ & $25.1(43.5)$ & $81.8(13.2)$ \\
\hline Difference & 3.1 & 24.6 & 10.6 & 0.9 & 18.7 \\
\hline
\end{tabular}

\subsection{Comparison of oxidation treatment method}

Electrolysis oxidation was achieved in this work. The authors performed plasma and ozone oxidation treatments in previous work ${ }^{7,8)}$. The results of these oxidation treatments are shown in Table 1, which compares the contact angles measured on untreated and treated chalcopyrite and molybdenite surface electrodes. The following treatments were performed: 800 -s electrolysis at $1.2 \mathrm{~V}, 30$-min ozone treatment, 1-min plasma treatment, and $120 \mathrm{~min}$ of washing after the plasma treatment. The data corresponding to the plasma and ozone treatment were taken from a previous paper ${ }^{7,8)}$ and oxidation procedure and condition is as follows. For ozone oxidation, massive mineral sample was suspended in $10^{-3} \mathrm{M}$ $\mathrm{KCl}$ at $\mathrm{pH} 9$ then dispersed with ultrasonic for 1 min followed by stirred at $700 \mathrm{rpm}$ with bubbling ozone for $30 \mathrm{~min}$. Ozone was produced from $2 \mathrm{~L} \mathrm{~min}^{-1}$ pure oxygen and ozone generation rate was about $2.4 \mathrm{~g} \mathrm{~h}^{-1}$. Ozone concentration in this gas is $20 \mathrm{~g} \mathrm{~m}^{-3}$. For plasma treatment, plasma treatment was carried out for massive mineral sample with plasma generator (Model PA 1504, Kyoto Denshi-Keisoku Co., Ltd.) at $10 \mathrm{~W}$ for 10 min by oxygen plasma at $100 \mathrm{~Pa}$ using a frequency of 13.56 MHz. After plasma treatment, sample washing was achieved as following procedure: plasma treated massive sample was suspended in a beaker with a solution of $\mathrm{pH} 9$ adjusted with potassium hydroxide (hereafter; $\mathrm{pH} 9$ solution) and magnetic stirred with bubbling oxygen for sample washing for $120 \mathrm{~min}$. The difference in the contact angle before and after oxidation in brackets in table. Also the difference in the contact angle between chalcopyrite and molybdenite is shown. As the table shows, high contact angles occur for both the untreated chalcopyrite and molybdenite. The contact angles differ only slightly and are therefore difficult to distinguish via flotation. However, the contact angles of the plasma-treated surfaces are considerably lower than those of the untreated surfaces. After washing, the contact angle of molybdenite recovered, but the contact angle of chalcopyrite was still lower than that of the untreated surface. The contact angle of both electrodes decreased with electrolysis and ozone oxidation, and the contact angle of oxidized chalcopyrite is lower than that of molybdenite. More importantly, the difference in the contact angles of the treated electrodes indicates that different floatability can be achieved with these treatments.

These results suggested following phenomenon: for untreated chalcopyrite and molybdenite, contact angle are high because of both hydrophobic property. After plasma treatment, both chalcopyrite and molybdenite contact angle became low since both were covered with hydrophilic oxidation products on the surface. Followed by water washing makes only molybdenite contact angle recovered since molybdenite oxide dissolution. with ozone oxidation treatment, both chalcopyrite and molybdenite contact angle became low since ozone is strong oxidants then both are oxidized. But molybdenite contact angle is higher than that of chalcopyrite since dissolution of molybdenite oxide. With electrolysis oxidation, it seems similar with ozone treatment but contact angle difference between chalcopyrite and molybdenite is higher than that of ozone treatment. It seems that chalcopyrite oxidation is preference more than molybdenite because of its resistivity difference.

The XPS results suggest that the surface of molybdenite is oxidized during plasma and ozone oxidation, i.e., oxygen is attached to the surface of the molybdenite layer. With washing after plasma treatment, molybdenum oxide is dissolved, probably as oxide ions such as $\mathrm{MoO}_{4}{ }^{2-}$, as indicated by the $\mathrm{pH}$-Eh diagram ${ }^{8,9)}$. As a result, the surface of molybdenite is preserved with washing.

These results indicate that oxyhydroxide and molybdenite oxide are deposited, through various oxidation methods, on the surface of chalcopyrite and molybdenite, respectively. A comparison of the XPS results and the oxide-coverage product on the surface of chalcopyrite revealed that greater levels of oxidation occur during ozone and electrolysis treatments than during plasma oxidation. In contrast, compared with ozone and electrolysis, the plasma treatment yields greater oxide-product coverage of the molybdenite surface. In other words, although plasma oxidation is weaker than ozone and electrolysis oxidation, molybdenum oxide persists on the surface of plasma-treated molybdenite because this oxidation is performed under dry conditions. Because molybdenum oxide is soluble in water, subsequent washing resulted in a decrease in the amount of molybdenum oxide on the surface. Ozone and electrolysis oxidation strongly oxidize chalcopyrite and molybdenite and depress flotation on both surfaces. Applying electrolysis oxidation to powder samples is difficult and improvements are required to realize selective flotation. Plasma oxidation is considered complex, because dry conditions are required for plasma application. The ozone treatment is applicable to selective flotation, but excessive oxidation ability and high cost hinder the realization of selective flotation. The knowledge provided by this work may be useful in developing new and efficient oxidation techniques for achieving selective flotation.

\section{Conclusions}

Electrolysis oxidation of chalcopyrite and molybdenite was investigated, via various electrochemical techniques, to elucidate the surface property regarding selective flotation of chalcopyrite and molybdenite. Both chalcopyrite and molybdenite exhibit high natural floatability with low surface wettability. However, oxidation treatments indicate that selective conversion of chalcopyrite wettability from hydrophobic to hydrophilic, while maintaining the hydrophobicity of the mo- 
lybdenite surface, can be achieved. This is possible during electrolysis, since the chalcopyrite surface is covered by iron sulfate and iron oxyhydroxide. During the retention process, the iron sulfate dissolves in the solution leaving only iron hydroxide, which is hydrophilic, on the chalcopyrite surface. However, oxidation of molybdenite is difficult owing to its low conductivity. The effect of oxidation, achieved via other oxidation methods, on the floatability of chalcopyrite and molybdenite is attributed to similar phenomena. In plasma and ozone oxidation, slightly produced molybdenum oxide can dissolve into the solution rendering the remaining molybdenite surface hydrophobic. The difference in hydrophobicity, after oxidation, indicates that selective flotation of chalcopyrite and molybdenite can be achieved.

\section{Acknowledgements}

This research was supported by Sumitomo Metal Mining, Co., Ltd., and by a Grant-in-Aid for Science Research (Nos. 15H02333 and 16K06929) from Japan Society for the Promotion of Science (JSPS).

\section{REFERENCES}

1) B.A. Wills: Wills' mineral processing technology, (Elsevier, Amsterdam, 2006).

2) S.M. Bulatovic: Handbook of Flotation Reagents: Chemistry, Theory and Practice, (Elsevier, Amsterdam, 2010).

3) A. Ansari and M. Pawlik: Miner. Eng. 20 (2007) 609-616.

4) G.Y. Liu, Y.P. Lu, H. Zhong, Z.F. Cao and Z.H. Xu: Miner. Eng. 36-38 (2012) 37-44.

5) M. Zanin, I. Ametov, S. Grano, L. Zhou and W. Skinner: Int. J. Miner. Process. 93 (2009) 256-266.

6) A. Ansari and M. Pawlik: Miner. Eng. 20 (2007) 600-608.

7) S. Chander: Int. J. Miner. Process. 72 (2003) 141-150.
8) T. Hirajima, M. Mori, O. Ichikawa, K. Sasaki, H. Miki, M. Farahat and M. Sawada: Miner. Eng. 66-68 (2014) 102-111.

9) T. Hirajima, H. Matsuoka, H. Miki, A.M. Elmahdy and K. Sasaki: Flotation'15, ed. by B. Wills, (MEI, 2015).

10) D.A. Shirley: Phys. Rev. B 5 (1972) 4709-4714.

11) H. Tributsch and J.C. Bennett: J. Electroanal. Chem. 81 (1977) 97-111.

12) R.P. Hackl, D.B. Dreisinger, E. Peters and J.A. King: Hydrometallurgy 39 (1995) 25-48.

13) T.C. Almeida, E.M. Garcia, H.W.A. Silva, T. Matencio and V.F.C. Lins: Int. J. Miner. Process. 149 (2016) 25-33.

14) S. Chander and D.W. Fuerstenau: Int. J. Miner. Process. 10 (1983) 89 94.

15) Z. Shuxian, W.K. Hall, G. Ertl and H. Knözinger: J. Catal. 100 (1986) $167-175$.

16) A. Ghahremaninezhad, D.G. Dixon and E. Asselin: Electrochim. Acta 87 (2013) 97-112.

17) F.M. Capece, V. Di Castro, C. Furlani and G. Mattogno: J. Electron Spectrosc. Relat. Phenom. 27 (1982) 119-128.

18) M.C. Biesinger, L.W.M. Lau, A.R. Gerson and R.S.C. Smart: Appl. Surf. Sci. 257 (2010) 887-898.

19) A.N. Buckley and R. Woods: Aust. J. Chem. 37 (1984) 2403-2413.

20) D. Brion: Appl. Surf. Sci. 5 (1980) 133-152.

21) B.J. Tan, K.J. Klabunde and P.M.A. Sherwood: Chem. Mater. 2 (1990) 186-191.

22) N.S. McIntyre and D.G. Zetaruk: Anal. Chem. 49 (1977) 1521-1529.

23) M.A. Fazal, A.S.M.A. Haseeb and H.H. Masjuki: Corros. Sci. 67 (2013) 50-59.

24) K. Sasaki, K. Takatsugi, K. Ishikura and T. Hirajima: Hydrometallurgy 100 (2010) 144-151.

25) S.L. Harmer, J.E. Thomas, D. Fornasiero and A.R. Gerson: Geochim. Cosmochim. Acta 70 (2006) 4392-4402.

26) R.V. Siriwardane and J.M. Cook: J. Colloid Interface Sci. 104 (1985) 250-257.

27) M.A. Baker, R. Gilmore, C. Lenardi and W. Gissler: Appl. Surf. Sci. 150 (1999) 255-262.

28) P. Gajardo, P. Grange and B. Delmon: J. Phys. Chem. 83 (1979) 17711779 .

29) J. Iranmahboob, S.D. Gardner, H. Toghiani and D.O. Hill: J. Colloid Interface Sci. 270 (2004) 123-126. 